\title{
Continent catheterizable conduits in pediatric urology: One-center experience
}

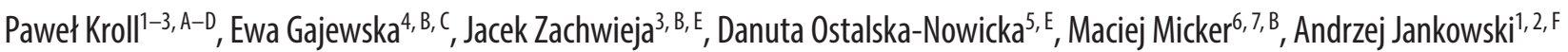 \\ 1 Department of Pediatric Surgery, Poznan University of Medical Sciences, Poland \\ 2 Department of Pediatric Urology, Poznan University of Medical Sciences, Poland \\ ${ }^{3}$ Neurology Unit, Poznan University of Medical Sciences, Poland \\ ${ }^{4}$ Department of Rehabilitation, Faculty of Physical Culture in Gorzów Wielkopolski, University School of Physical Education in Poznań, Poland \\ ${ }^{5}$ Department of Pediatric Nephrology, Poznan University of Medical Sciences, Poland \\ ${ }^{6}$ Department of General and Vascular Surgery, Poznan University of Medical Sciences, Poland \\ ${ }^{7}$ Department of Angiology, Poznan University of Medical Sciences, Poland \\ A - research concept and design; $\mathrm{B}$ - collection and/or assembly of data; $\mathrm{C}$ - data analysis and interpretation; \\ $D$ - writing the article; $E$ - critical revision of the article; $F$ - final approval of article
}

Address for correspondence

Paweł Kroll

E-mail: pawelkroll.poczta@gmail.com

Funding sources

None declared

Conflict of interest

None declared

Received on December 21, 2015

Revised on March 17, 2016

Accepted on May 5, 2016

DOI

$10.17219 /$ acem/63032

\section{Copyright}

Copyright by Author(s)

This is an article distributed under the terms of the

Creative Commons Attribution Non-Commercial License

(http://creativecommons.org/licenses/by-nc-nd/4.0/)

\section{Abstract}

Background. Clean intermittent catheterization (CIC) is a standard treatment for patients who are unable to empty the bladder. In the absence of the urethra or if catheterization through the urethra is problematic, a continent vesicostomy is used as a catheterizable conduit. The Malone procedure is an established treatment option for children with neurogenic constipation and fecal incontinence.

Objectives. The aim of the study was to report the authors' experience with continent catheterizable conduits (CCCS) in children, to review the results and to determine the efficacy of the technique, with an emphasis on continence and the need for revision.

Material and methods. The retrospective study involved children who underwent catheterizable conduit procedures from 2000 to 2015. Two kinds of continent stomas were performed: Mitrofanoff vesicostomies for $\mathrm{CIC}$ and Malone antegrade continence enemas (MACEs). The 115 patients treated included 66 girls and 49 boys. A total of 134 operations were performed; 62 were Mitrofanoff vesicostomies and 72 were Malone appendicostomies. In 19 cases, both Mitrofanoff and Malone appendicostomies were formed out of 1 appendix divided into 2 parts. In 5 children vesicocutaneous stomas were constructed using Monti's procedure, and in 1 it was constructed from an intussuscepted ileal loop. In 27 patients Malone procedures were performed laparoscopically.

Results. The mean follow-up period was 8.6 years. There was no serious morbidity in relation to the surgery. In 9 children local wound infection was noted, and in 9 others stomal stenosis developed. Out of the 62 children with catheterizable vesicostomies, 59 were continent. The MACE procedure was successful in all 72 patients; problems with constipation and fecal incontinence were resolved in all cases. None of the laparoscopies needed conversion.

Conclusions. Continent catheterizable conduits help patients achieve both fecal and urinary continence. Laparoscopy is effective in performing the Malone procedure. Stoma-related complications could be avoided using end-to-side appendix anastomoses to the skin. Stomal incontinence is rare even when a simplified technique is employed, using the appendix without cecoplication.

Key words: surgery, urinary incontinence, child, neurogenic bladder, fecal incontinence 
Severe impairment of bladder function can arise from various causes. The most common cause of bladder dysfunction in children is spinal dysraphism. Other causes, such as developmental defects (an imperforate anus, sacral tumors or sacral agenesis), accidental injuries or spinal tumors are rare. ${ }^{1-3}$

In children with severe bladder dysfunction, the therapeutic strategy is focused on 2 tasks: preservation of renal function and control of micturition, maintaining urinary continence. For those purposes, a continent, low-pressure, high-volume bladder is essential.

This is achieved by ensuring complete emptying of the bladder. ${ }^{1-3}$

Since 1972, clean intermittent catheterization (CIC) has been the standard treatment for patients who are unable to empty the bladder. ${ }^{4}$ If catheterization through the urethra is problematic or in rare cases of the absence of the urethra, a continent vesicostomy (CVS) is performed to create a continent catheterizable conduit (CCC). In Paul Mitrofanoff's original description from 1980, the CCC is made from the appendix. ${ }^{5-7}$

With improved urological care and the introduction of CIC and oral anticholinergics, the majority of children with neurogenic bladders survive into adulthood expecting the best quality of life. Decreased bladder capacity can be effectively treated with oral anticholinergics, but in some children, bladder augmentation or bladder replacement has to be performed. CIC is mandatory to empty an augmented bladder; in some children the use of a Mitrofanoff stoma is required. ${ }^{5-8}$

Children with neurogenic bladder also encounter serious problems with defecation and fecal incontinence. The first line therapy for neurogenic constipation is conservative treatment with dietary recommendations, mineral-based and osmotic sugar laxatives, suppositories and enemas. In most cases, this kind of treatment proves

Table 1. The types of conduit procedures performed

\begin{tabular}{|c|c|}
\hline Procedures & Number of children \\
\hline $\begin{array}{l}\text { Creation of CVS into the native bladder } \\
\text { including: } \\
\text { - using the appendix } \\
\text { - using the Monti technique }\end{array}$ & $\begin{array}{l}11 \\
6 \\
3\end{array}$ \\
\hline $\begin{array}{l}\text { Creation of CVS for BA or BR } \\
\text { including: } \\
\text { - using the appendix } \\
\text { - } 2 \text { stomas (MACE + CVS) from a divided } \\
\text { appendix } \\
\text { - using the Monti technique } \\
\text { - CVS from intussuscepted ileal loop }\end{array}$ & $\begin{array}{r}51 \\
48 \\
19 \\
2 \\
1\end{array}$ \\
\hline $\begin{array}{l}\text { MACE appendicostomy (open surgery) } \\
\text { including: } \\
\text { - } 2 \text { stomas (MACE + CVS) from a divided } \\
\text { appendix }\end{array}$ & $\begin{array}{l}45 \\
19\end{array}$ \\
\hline $\begin{array}{l}\text { Laparoscopic assisted MACE } \\
\text { appendicostomy }\end{array}$ & 27 \\
\hline
\end{tabular}

CVS - continent vesicostomy; BA - bladder augmentation; BR - bladder replacement; MACE - Malone antegrade continence enema. very effective. Children with meningomyelocele are especially difficult to deal with because constipation caused by prolonged colonic transit time is accompanied by fecal and gas incontinence caused by sphincter dysfunction. Surgical treatment is considered in patients for whom non-invasive treatment methods related to stool consistency, its retention and the ability to control defecation have proved ineffective. The Malone antegrade continence enema (MACE) procedure is an established treatment option for children with chronic neurogenic constipation and fecal incontinence. The aim of the Malone procedure is to use the appendix as a CCCs for antegrade colonic enema (ACE). ${ }^{9-12}$

The aim of the study was to report the authors' experience with CCCs in children, to review the results and to determine the efficacy of the technique, with an emphasis on continence and the need for revision.

\section{Material and methods}

The retrospective study included children who underwent CCC procedures at the Department of Pediatric Surgery at Poznan University of Medical Sciences (Poland) between 2000 and 2015. Two kinds of continent stomas were performed: Mitrofanoff CVS for CICs and Malone appendicostomies for ACE procedures. A total of 115 patients were treated, comprising 66 girls and 49 boys. The patients' mean age at the time of the operation was 9.4 years (age range: $2-17$ years). A total of 134 CCCs were created by a single surgeon, of which 62 (46\%) were CVS for CICs and 72 (56\%) were MACE appendicostomies; in 19 cases (14\%) both stomas were created from a single divided appendix. The types of conduit procedures are shown in Table 1.

\section{Continent vesicostomies}

In the study period, 62 CVSs were performed to create channels for CICs. The mean age of the children who underwent this procedure was 8.8 years (age range: $2-17$ years). The Mitrofanoff operation was performed to provide alternative access to the bladder. It was performed as an additional procedure accompanying bladder augmentation, or as a separate operation in boys with preserved sensation in the urethra (in the case of boys who had undergone bladder exstrophy and boys with complications following posterior urethral valve resection).

CVS was also proposed for girls with neurogenic bladder who had technical problems with self-catheterization and for all patients undergoing bladder replacement procedures. In 46 children, CVS was an additional procedure at the time of bladder augmentation (BA); in 5 it was performed during a bladder replacement (BR) operation; in 11 children CVSs were created for CIC of a native neurogenic bladder; and in 19 cases both Mitrofanoff and 
Malone appendicostomas were formed out of 1 appendix divided into 2 parts.

The appendix was used for CVS whenever possible; in 5 cases a flap of the small intestine was employed using the Monti technique, and in 1 case a catheterizable stoma was made of an intussusception ileal nipple.

\section{MACE procedures}

The 64 patients qualified for MACE operations were those with chronic intractable neurogenic constipation and fecal and gas incontinence. The mean age of these patients was 9.3 years (age range: $5-17$ years). In 54 of these children defecation problems were caused by a dysraphic defect of the lumbar and sacral regions of the spine; in 3 patients the problems were caused by sacral agenesis; and in 1 patient by a sacrococcygeal tumor. In 4 of the children, constipation and fecal incontinence remained after a posterior sagittal anorectoplasty for an imperforate anus. In all the MACE operations, the appendix was used as a CCC.

The underlying causes of the need for a CCC are listed in Table 2.

Table 2. The causes of bladder and bowel dysfunction

\begin{tabular}{|l|c|c|}
\hline \multirow{2}{*}{\multicolumn{1}{|c|}{ Cause of dysfunction }} & \multicolumn{2}{|c|}{ Number of children } \\
\cline { 2 - 3 } & MACE & CVS \\
\hline $\begin{array}{l}\text { Status post cystectomy } \\
\text { rhabdomyosarcoma (RMS) }\end{array}$ & - & 5 \\
\hline Open meningomyelocele (MMC) & 56 & 32 \\
\hline $\begin{array}{l}\text { Other defects of the nervous } \\
\text { system (occult spinal dysraphism, } \\
\text { sacral agenesis, tumor) }\end{array}$ & 4 & 7 \\
\hline Cerebral palsy & - & 3 \\
\hline Bladder exstrophy & - & 7 \\
\hline Posterior urethral valves & - & 6 \\
\hline Imperforate anus & 4 & 2 \\
\hline Total & 64 & 62 \\
\hline
\end{tabular}

The MACE operations were carried out either by classic open surgery or by a laparoscopically assisted technique (LACE procedure). The classic operations were performed on 45 patients as an additional procedure during the augmentation of the bladder. In the 27 patients who underwent the MACE operations as a separate procedure, it was performed laparoscopically.

In the LACE operations, an umbilical port was used for the camera with 2 or 3 additional ports. Two ports were used in 25 patients, and in the 2 remaining cases, a $3^{\text {rd }}$ port was used. Once the cecum and appendix were located, mobilized and freed of any adhesions, a skin incision was made and the distal part of the appendix was brought out of the peritoneal cavity with the aid of laparoscopic tools. In the first 23 procedures, an anastomosis of the spatulated tip of the appendix with a tubularized skin flap was performed.
In subsequent operations, a simplified procedure was used: the distal tip of the appendix was anastomosed directly end-to-side to the skin tube. An 8Fr Foley catheter was used to stent the appendicocutaneous anastomosis for 2 weeks.

The original description of the Malone procedure relied on a reversed, tunneled and reimplanted appendix. In all the cases in the present study, a simplified in situ procedure was performed, using the appendix as a CCC without cecoplication. This requires minimal mobilization of the appendix and minimal manipulation of the blood supply. In neither Mitrofanoff nor Malone procedures there was any anti-reflux tunneling of the proximal part of the appendix performed, as the continence mechanism is a function of the appendix length and the mucosal coaptation of the appendiceal lumen. Especially in cases in which MACE and CVS were formed from a divided appendix, the length of the 2 conduits was too short to allow a surgical creation of any rational anti-reflux mechanism.

Starting $48 \mathrm{~h}$ after the operation, daily infusions were made through a catheter.

The catheter remained in the stoma for at least 2 weeks after the operation. Afterwards, patients catheterized their MACE stoma channels every day, making infusions every $2^{\text {nd }}$ or $3^{\text {rd }}$ day.

\section{Results}

The mean follow-up period was 8.6 years (ranging from 1 to 15 years). There was no mortality or serious morbidity in relation to the surgery. In 7 children (9.7\%) who underwent MACE procedures and in $2(3.2 \%)$ who underwent CVS, local wound infection was managed conservatively; however, partial dehiscence in the skin part of the fistula in 2 children resulted in channel shortening. In 1 patient, complete destruction of the skin part of the channel occurred.

All MACE and CVS stomas were catheterized easily with a 6-10 Fr feeding tube. Stomal stenosis requiring dilation in the office was observed in 6 children (8.3\%) who had had MACE procedures and in $3(4.8 \%)$ of those who had had CVS procedures. Four children were reoperated. All 9 of these strictures developed in the first 6 months after the surgery, and they were all observed in the cases of cutaneo-appendico anastomosis with a tubular skin flap.

Out of the 62 CVS children, 59 (95\%) were continent. One child with an appendix CVS and 1 with a Monti CVS had mild urine leakage at maximal bladder capacity; and a girl who had had BR surgery and a CCC made from an intussusception ileal nipple remained incontinent after reoperation and finally decided to be diverted with a Bricker stoma.

In all the children in the study, the MACE operation was successfully performed by both classic and LACE 
techniques. There was no need for conversion in any of the LACE procedures. The laparoscopic method permitted precise location of the appendix and its mobilization, freeing it from any adhesions, and made it easy to bring the appendix out of the peritoneum. The use of a $3^{\text {rd }}$ port for the needle-holder to fix the cecum to the undersurface of the abdominal wall prolonged the procedure and made it more complicated.

Following MACE procedures, 59 (92\%) out of 64 patients were continent; in 5 patients $(7.8 \%)$ mucus leakage from the MACE stoma was observed and treated with dressing. One patient underwent successful surgical revision of a stoma with cecoplication.

In long term observation, $92 \%$ of the MACE conduits were still in use. In 3 children (4.6\%), the MACE stoma closed because of discontinued catheterization. In 1 child, the perforation of the MACE channel was treated conservatively, but the stoma closed.

Problems with constipation and fecal incontinence were resolved in all cases of the MACE operation. In 1 patient, voluntary defecation without the need for infusions was observed within a few months after the ACE treatment. The patient's parents decided to give up catheterization and ACE.

The overall complications rate is shown in Table 3.

Table 3. Complications of CCC procedures

\begin{tabular}{|l|c|c|}
\multirow{2}{*}{\multicolumn{1}{c|}{ Complication }} & \multicolumn{2}{c|}{ Number of children } \\
\cline { 2 - 3 } & MACE & CVS \\
\hline Wound infection & 7 & 2 \\
\hline Stoma stenosis & 6 & 3 \\
\hline Leakage of urine & - & 3 \\
\hline Mucus leakage & 5 & - \\
\hline Stoma closure & 5 & - \\
\hline Stoma perforation & 1 & - \\
\hline Reoperation & 3 & 3 \\
\hline Total & $27(42 \%)$ & $11(17 \%)$ \\
\hline
\end{tabular}

\section{Discussion}

The aim of conduit procedures is to provide a channel for intermittent catheterization that is continent, easily accessible and painless. The indications for constructing a CCC are neurogenic bladder, inability to void with urine incontinence and refractory neurogenic constipation with fecal incontinence.

Great improvements in the treatment of patients with neurogenic bladder was made with the introduction of CIC by Jack Lapides in 1971. The next important step was made by Paul Mitrofanoff in 1980, who proposed using the appendix as an alternative continent channel for CIC in patients with urethral strictures. Other tubular structures have also been proposed as CCC alternatives when the appendix is not available, including a fallopian tube, the ureter or a short segment of retubularized small bowel (the Monti technique). ${ }^{5-7,11-17}$

$\mathrm{CIC}$ with a CCC enabled further development of reconstructive urology by applying the ideas of Jan Mikulicz-Radecki, a surgeon based in Wrocław, Poland, who in 1899 was the first to describe the use of parts of the digestive tract for bladder reconstruction. ${ }^{18}$

The mean age of the children in the present study was 9.4 years, similar to those in the studies by VanderBrink et al., Bani-Hani et al. and Süzer et al. ${ }^{5,12,13}$ In the majority of cases the bladder and bowel dysfunctions were caused by meningomyelocele. Those observations are consistent with other studies. ${ }^{6,12-14}$

In the present study, CCCs for bladder CIC were created from the appendix in the majority of the patients (128), in 19 children they were formed from a divided appendix, and 5 Monti tubes were constructed. Similar ratios were reported by Süzer and Castellan. ${ }^{5,16}$

In augmented patients, CVS was proposed as an additional procedure, especially for boys with preserved urethra sensation and for girls with technical problems with self-catheterization. In children selected for the Mitrofanoff procedure on their native bladders, no bladder neck surgery was performed, as all of them had proper age-related bladder volume with leak-point pressure $>20 \mathrm{~cm} \mathrm{H}_{2} \mathrm{O}$.

Most of the children in the present study became continent: $95 \%$ of those who underwent CVA and $92 \%$ of those who had MACE procedures. One girl with a CVS made of an intussuscepted ileal loop remained completely incontinent, and was diverted. In 1 boy with an appendiceal CCC and 1 with a Monti tube, minor leakage from the CVS was observed at maximal bladder capacity, with no need for correction in the patients' opinion. The continence rate in the patients in the present study is similar to that reported by Clark et al., Farrugia and Malone, and Castellan et al., with similar complication rates. ${ }^{14-16}$

McAndrew and Malone assessed the outcomes of 112 CCC channels, both CVA and MACE, and did not find any difference in the incidence of complications between the 2 types of conduit. They reported that $93 \%$ of the MACE conduits were continent, but stomal stenosis occurred in 29\% of the CVS; stenosis was less common with Monti tubes than with appendix CCCs. ${ }^{17}$ Castellan et al. found no difference in the incidence of complications in Monti vs appendix conduits. ${ }^{16}$

Chronic constipation accompanied by fecal and gas incontinence is a real problem in patients suffering from a neurogenic bladder. The mechanisms leading to neurogenic constipation and urine incontinence are similar. Spine malformations or injuries in the lumbosacral region can damage somatic and autonomic sensory and motor fibers, as well as spinal centers. All the patients in the present study had unsuccessfully tried conservative treatments, following dietary recommendations, oral herbal and synthetic, osmotic and stimulant laxatives 
and, as a last resort, used suppositories and colonic enemas. Whenever that kind of treatment proved ineffective, surgery was recommended.

The idea of using the appendix as a CCC in children with chronic constipation was conceived in 1989 by P.S. Malone. This stoma was supposed to serve for isoperistaltic antegrade colonic enema (ACE) for colonic washout. A year later, the author described this method in The Lancet. In the first 21-patient group assessed by the author, the continent appendicocecostomy was created with or without reversal of the appendix. The tip of the appendix was anastomosed to a skin tube to avoid problems with exposed mucosa. ${ }^{9-11,14}$ Many modifications of the original technique have been described. This stoma has been applied in both the ascending and descending colon. ${ }^{19}$ The Malone operation can be an additional procedure during the augmentation and reconstruction of the bladder. ${ }^{11,14-16}$ When the surgical anatomy is amenable, the appendix can be used for the creation of both MACE and CVA conduits. The split-appendix technique was used in $14 \%$ of the patients in the present study. In a series of 394 children reported by VanderBrink et al., the split-appendix technique was used in $11 \%$ of the patients. ${ }^{12}$

The MACE operation was originally described by Malone as a procedure performed in the classic fashion with 2 incisions. This has been adapted to a laparoscopeassisted technique (LACE). To perform a LACE procedure 2 ports are needed, and an incision in the skin made in a place chosen during the laparoscopy, which is then used to make the stoma outlet. In the LACE technique, the appendix is not reversed. ${ }^{19-22}$

In 2 patients in the present study, a $3^{\text {rd }}$ port was used for the needle-holder for the purpose of fixing the cecum to the abdominal wall. This solution, however, was not useful. Manipulation with the needle-holder is complicated and makes the procedure longer in comparison to the simplified technique, where the cecum is left untouched.

The LACE operation is not always possible and some patients need conversion to classic operation. However, in the present study none of the LACE patients required conversion.

In the first 18 patients, the end portion of the MACE stoma was made of a flap of skin and joined to the end of the appendix. Creating such a skin channel results in a better cosmetic effect, although it may cause complications. ${ }^{11,12,14,16,17,20}$ In 3 of the LACE patients in the current study, local infection of the wound occurred, and in 6 of those patients strictures developed. According to other authors, such minor complications may be present in $10-81 \%$ of MACE operations, with stoma stenosis in about $20-30 \%$. The results of the present study are comparable with those from the literature, but with a lower incidence of stomal stenosis. ${ }^{12-14,16,17,23,24}$

Narayanaswamy et al. suggested that $26 \%$ of patients with appendicovesicostomy and $60 \%$ of patients with ileovesicostomy have difficulty with catheterization. ${ }^{24}$
To avoid complications of stenosis, the current authors suggest not reversing the appendix for CVS and MACE. It is preferable not to do any cecoplication with direct anastomosis of the conduit to the skin.

Another complication after Malone procedures is $\mathrm{mu}$ cus leakage from the stoma, occurring in $5-15 \%$ of patients. ${ }^{10-12,14,16,17,23,24}$ In the present study, it was seen in $7.8 \%$ of children.

In long-term observation, $92 \%$ of the conduits in the present study group were still in use, which is similar to what was reported by Farrugia and Malone, and Lamelle et al. ${ }^{15,25}$

Although no procedures aimed at creating valve mechanisms between the appendix and the cecum were performed in the present study, the number of patients with complications was close to that reported in the literature. ${ }^{10-12,14,16,17,23-25}$ Secondary ischemia, adhesions and scar formation are reduced, alleviating the most common complication, stoma stenosis. These results also show that cecoplication is not necessary to maintain stomal continence after MACE.

\section{Conclusions}

Continent catheterizable conduits help patients achieve both fecal and urinary continence.

Laparoscopy is effective in performing Malone operations.

Stoma-related complications can be avoided using endto-side appendix anastomoses to the skin. Stomal incontinence is also rare when a simplified technique, using the appendix without cecoplication, is employed.

\section{References}

1. Verpoorten C, Buyse GM. The neurogenic bladder: Medical treatment. Pediatr Nephrol. 2008;23:717-725.

2. Panicker JN, Fowler CJ, Kessler TM. Lower urinary tract dysfunction in the neurological patient: Clinical assessment and management. Lancet Neurol. 2015;14:720-732.

3. Fowler CJ, Griffiths D, de Groat WC. The neural control of micturition. Nat Rev Neurosci. 2008;9:453-466.

4. Lapides J, Diokno AC, Silber SJ, Lowe BS. Clean intermittent selfcatheterization in the treatment of urinary tract disease. $J$ Urol. 1972;107:458-461.

5. Süzer O, Vates TS, Freedman AL, Smith CA, Gonzalez R. Results of the Mitrofanoff procedure in urinary tract reconstruction in children. Br J Urol. 1997;79:279-282.

6. Gerharz EW, Tassadaq T, Pickard RS, Shah PJ, Woodhouse CR, Ransley PG. Transverse retubularized ileum: Early clinical experience with a new second line Mitrofanoff tube. J Urol. 1998;159:525-528.

7. Singh G, Thomas DG. Intermittent catheterization following enterocystoplasty. Br J Urol. 1995;76:175-178.

8. González R, Ludwikowski BM. Alternatives to conventional enterocystoplasty in children: A critical review of urodynamic outcomes. Front Pediatr. 2013;1:1-9.

9. Malone PS, Ransley PG, Keily EM. Preliminary report: The antegrade continence enema. Lancet. 1990;336:1217-1218.

10. Griffiths DM, Malone PS. The Malone antegrade continence enema. J Pediatr Surg. 1995;30:68-71.

11. Wimpissinger TF, Gerharz EW, Malone PS. Chirurgische Therapie der Stuhl-Überlaufinkontinenz: Vorgehensweise nach der Malone-antegrade-continence-enema-Technik. Dtsch Arztebl. 2002;43:2279-2283. 
12. VanderBrink BA, Cain MP, Kaefer M, Meldrum K, Misseri R, Rink RC. Split-appendix technique for simultaneous appendicovesicostomy and appendicocecostomy. J Pediatr Surg. 2011;46:259-262.

13. Bani-Hani AH, Cain MP, Kaefer M, et al. The Malone antegrade continence enema: Single institutional review. J Urol. 2008;180:1106-1110.

14. Clark T, Pope JC IV, Adams MC, Wells N, Brock JW III. Factors that influence outcomes of the Mitrofanoff and Malone antegrade continence enema reconstructive procedures in children. $J$ Urol. 2002;168:1537-1540.

15. Farrugia MK, Malone PS. Educational article: The Mitrofanoff procedure. J Pediatr Urol. 2010;6:330-337.

16. Castellan MA, Gosalbez R, Labbie A, Ibrahim E, DiSandro M. Outcomes of continent catheterizable stomas for urinary and fecal incontinence: Comparison among different tissue options. BJU Int. 2005;95:1053-1057.

17. McAndrew HF, Malone PS. Continent catheterizable conduits: Which stoma, which conduit and which reservoir? BJU Int. 2002;89:86-89.

18. Mikulicz J. Zur operation der augeborenen blasenspalte. Zentralbl. Chir. 1899;26:641-643.

19. Sinha CK, Butler $C$, Haddad $M$. Left antegrade continent enema (LACE): Review of the literature. Eur J Pediatr Surg. 2008;18:215-218.

20. Lynch AC, Beasley SW, Robertson RW, Morreau PN. Comparison of results of laparoscopic and open antegrade continence enema procedures. Pediatr Surg Int. 1999;15:343-346.

21. Lawal TA, Rangel SJ, Bischoff A, Peña A, Levitt MA. Laparoscopic-assisted Malone appendicostomy in the management of fecal incontinence in children. $J$ Laparoendosc Adv Surg Tech A. 2011;21:455-459.

22. Van Savage JG, Yohannes P. Laparoscopic antegrade continence enema in situ appendix procedure for refractory constipation and overflow fecal incontinence in children with spina bifida. J Urol. 2000;164:1084-1087.

23. Curry Jl, Osborne A, Malone PS. How to achieve a successful Malone antegrade continence enema. J Pediatr Surg. 1998;33:138-141.

24. Narayanaswamy B, Wilcox DT, Cuckow PM, Duffy PG, Ransley PG. The Yang-Monti ileovesicostomy: A problematic channel? BJU Int. 2001;87:861-865.

25. Lemelle JL, Simo AK, Schmitt M. Comparative study of the YangMonti channel and appendix for continent diversion in the Mitrofanoff and Malone principles. J Urol. 2004;172:1907-1910. 